\title{
Dimensiones discursivas del sistema de sexo y género entre los indígenas zapotecas del Istmo de Tehuantepec (México)
}

\author{
Águeda Gómez Suárez \\ Universidad de Vigo (España) \\ Marinella Miano Borusso \\ Escuela Nacional de Antropología e Historia (México)
}

\section{Resumen}

La interacción social entre géneros se ha ido modificando históricamente, puesto que se trata de un sistema relacional que varía según las coordenadas sociales, económicas o culturales de cada época y de cada espacio concretos. Uno de los territorios insólitos y singulares donde la relación de género es excepcionalmente horizontal, se encuentra en la ciudad indígena zapoteca de Juchitán, ubicada en el Istmo de Tehuantepec (México), donde algunos autores han llegado a afirmar que existe un moderno sistema matriarcal. Con este artículo, dentro del ámbito de temáticas en torno al género y a la etnicidad en América Latina, se pretende reflexionar sobre las causas que han determinado que, entre la sociedad juchiteca, la mujer sea protagonista de la vida social a través de la situación ideológica y cultural dominante en la sociedad juchiteca.

Palabras clave: indígenas, sistema de sexo y género, zapotecas, matriarcado, estructuras ideológicas.

Abstract. Discursive dimensions on the system sex/gender between the aborigens zapotecas of Tehuantepec's isthmus

The social interaction among genders has being historically modified because it is a relational system which varies according to the social, economic or cultural aspects of each concrete time and space. One of the unusual and singular territories where gender relationships are exceptionally horizontal, can be found in the Zapotecan indigenous town of Juchitan, located in the Tehuantepec Isthmus (Mexico), where some authors have end up affirming that a modern matriarchal system exists. This paper placed under gender and ethnic Latin American movements thematic, is sought to meditate on the determinant causes of why woman are a constitutional part of a social movement which has generated great and significant transformations among the Juchitecan society.

Key words: indigenous, sex-gender system, zapotecs, matriarchal, ideologicals structures. 


\section{Sumario}

1. La universalidad de los sistemas de género

2. La población zapoteca del Istmo 3. Marco teórico y metodológico 4. Investigaciones previas
5. Las ideologías sexuales entre los zapotecas del Istmo

6. A modo de conclusión

Bibliografía

\section{La universalidad de los sistemas de género}

La interacción social entre las personas ha estado históricamente regulada por el género y la identidad sexual. Se trata de sistemas relacionales que han variado según las coordenadas sociales, económicas o culturales de cada época y de cada espacio concretos. Recientes enfoques críticos (Ortner, 1979; Keohane y otros, 1981; Heritier, 2002; Moore, 1991; Mérida, 2002) han discutido las categorías y los conceptos «universales» utilizados para aplicar en el proceso científico de análisis de la realidad, por su excesivo androcentrismo, etnocentrismo o heterocentrismo. Postulados tales como la universalidad de la subordinación social de la mujer como realidad transhistórica y pancultural pretende ser cuestionada en esta propuesta reflexiva. Para ello, se ha decidido optar por un estudio de caso en torno a la realidad que se presenta en otros lugares donde el orden sociosimbólico patriarcal no domina la articulación de las relaciones sociales.

Uno de los territorios singulares donde los vínculos sociales y, por ende, las relaciones entre sexo y género son excepcionales, se encuentra en la ciudad indígena zapoteca de Juchitán, ubicada en el Istmo de Tehuantepec (México), donde la preeminencia del papel social de la mujer ( «sistema matriarcal» $\left.{ }^{1}\right)$ y la institucionalización de un "tercer género» (el muxe) son los rasgos más sobresalientes de esta sociedad ${ }^{2}$. Frente a los postulados que consideran que los tra-

1. Existen tres posturas teóricas claramente diferenciadas en torno a la calificación de la sociedad juchiteca como matriarcado. Por un lado, autoras como la alemana Verónica BennholdtThomsen (1994) apoyan este postulado, en oposición a las ideas defendidas por antropólogas como Beverly Newbold Chiñas (1975), quien defiende que lo correcto sería utilizar el concepto de "matrilocalidad», y a las posturas de Marinella Miano (2002), quien niega ambas etiquetas.

2. En el Istmo de Tehuantepec, la constancia escrita de la presencia de homosexuales se remonta al siglo XVI. En la actualidad, el homoerotismo, las prácticas homosexuales, junto con el afeminamiento y el travestismo están institucionalizados y funcionan como un «tercer género» socialmente concebido, permitido y aceptado. Los muxe's son parte natural y normal de la composición genérica de la sociedad, y son valorados por su papel económico y cultural (Collins, 1986; Bennholdt-Thomsen, 1997, en Miano, 2002: 17). La sociedad juchiteca está orgullosa de la aceptación social de la "gaycidad» (Miano, 2002: 192), donde el estatus del muxé, su visibilidad social y sus funciones sociales específicas tienen que ver con la marcada división de roles sociales y con la situación de la mujer en la familia y en la comunidad. En el caso de las nguiu (término que puede traducirse como 'marimacha', pero 
bajos antropológicos sobre el «otro» se ubican en un «inframundo etnográfico» o "museo del primitivismo», este estudio quiere subrayar la sincronicidad temporal entre estas sociedades y Occidente (Campbell y Green, 1999: 105). La senda que se ha adoptado en el presente trabajo, se apoya en el paradigma constructivista, que entiende que «las realidades sociales» son construcciones históricas y cotidianas de actores individuales y colectivos. El "género" y el «sexo» son entendidos como constructor o elementos «imaginados» en circunstancias particulares y por razones específicas, de carácter contingente y transitorio (Moore, 1991; Heritier, 2002; Mérida, 2002).

En este texto, se pretende indagar en los elementos que permiten la permanencia en la actualidad de los sistemas de sexo y género más igualitarios. Si la literatura etnográfica sobre el «caso zapoteco» había concluido que el poder económico, social y político de las mujeres zapotecas del Istmo explicaba su igualdad respecto al hombre, en esta investigación se pretende comprobar si la existencia de una «ideología cultural de género» no patriarcal es un factor que también favorece esta igualdad.

\section{La población zapoteca del Istmo}

Las referencias a las mujeres zapotecas del Istmo como «amazonas matriarcales primitivas» y exóticamente hermosas se remonta al siglo XVI, cuando los primeros cronistas destacan la elegancia, la fuerza, la indomable sexualidad y el bello exotismo de estas mujeres ${ }^{3}$. Esto ha inspirado a intelectuales y a artistas contemporáneos tales como Frida Kahlo, Tina Modotti, Diego Rivera, Miguel Covarruvias, Elena Poniatowska, Graciela Iturbide, etc., quienes han percibido a la mujer juchiteca del Istmo como el símbolo del empowerment femenino y se han imbuido en su especial estética y plasticidad para realizar sus obras literarias, pictóricas o fotográficas.

El Istmo, la región donde se ubica la ciudad de Juchitán, es la zona más estrecha de América del Norte, con clima tropical, cálido y seco. Se trata de una región interétnica donde han convivido grupos cultural y lingüísticamente diferentes, pero relacionadas por el comercio que se remonta al periodo colonial (Barabás y otros, 2004; Reina, 1997: 348). La población de Juchitán se acerca a los 100.000 habitantes (INEGI, 1990), y los zapotecas constituye el grupo étnico más numeroso del estado de Oaxaca. El 73\% de la población habla zapoteco y el $85 \%$ también sabe hablar castellano. La lengua zapoteca

sin la connotación negativa occidental), no existe institucionalización social de su "estatus», ya que no cumple ninguna función social propia y su grado de transparencia pública es menor.

3. Así consta en los escritos del cronista colonial Torres de Laguna, publicados en 1580; en los textos del oficial colonial Manso de Contreras, en 1661; en la obra del arqueólogo francés Desiré Charnay, realizada durante los años 1857 y 1861; en el trabajo del explorador alemán G. F. von Thempsy, publicado en 1858, y en la obra del abate y viajero francés Charles Etienne Brasseur de Bourbourg, quien escribe en el año 1861 sobre el Istmo y sus mujeres (Campbell y Green, 1999). 
del Istmo es el didxazá (didxa: 'palabra'; zaa: 'nube'), de la familia zapotecana del grupo de lengua otomangue (Miano, 2002). Según los censos de 1990, el sector primario ocupa un $23 \%$ de la economía del municipio, el secundario ocupa un $30,9 \%$ y un $43 \%$ se dedica al sector terciario. El núcleo familiar dominante es trigeneracional y las relaciones de parentesco han funcionado como un mecanismo amortiguador de las diferencias económicas y sociales (Miano, 2002: 15). En Juchitán, durante los años setenta y ochenta, se desarrolló un movimiento político, la $\mathrm{COCEI}^{4}$, de claro perfil étnico y socialista, que obtendrá múltiples logros políticos a lo largo de su historia (Campbell, 1994, 1999; Rubin, 1997).

Juchitán, la antigua Xabizende ${ }^{5}$, fue un asentamiento hecho por Cosijoppi, el primer rey zapoteca, en vísperas de la llegada de los españoles, con el fin de ocupar una zona geoestratégica de comunicación importante. En el siglo XIX, la modernización del Istmo provocó el enriquecimiento de esta etnia frente a otros grupos étnicos oaxaqueños y en la emergencia de una élite zapoteca (Reina, 1997: 340, 349).

$\mathrm{Su}$ organización social es de tipo reticular, donde todos han establecido relaciones intensas y fuertes entre sí a través del vínculo de parentesco ${ }^{6}$ y vecindad. Los "nodos individuos» por los que discurre el mayor número de densidad relacional suelen ser las madres, las matriarcas de un «clan» familiar. La importancia del «bien común» frente al «bien individual y la lógica de la reproducción cultural» (Wieviorka, 2004) frente a la lógica de la "producción cultural» determina sus acciones sociales, que siempre deben beneficiar a la comunidad y a la tradición: "[...] aquí existe algo que es la "gracia", [...] cada quien tiene su "gracia", cada ser humano tiene un valor»"

\section{Marco teórico y metodológico}

Para iniciar este estudio en torno a las principales «ideologías culturales de género» dominantes en los discursos de la población juchiteca, se ha optado por utilizar la perspectiva teórica del «Frame analysis» o los «Marcos de interpretación ${ }^{8}$. Esta categoría analítica, el frame, proviene del interaccionismo

4. Esta organización se funda en el año 1974 con el nombre de Coalición de Campesinos y Estudiantes Juchitecos (CCEJ), posteriormente, en 1975, año en que se convierte en Coalición de Obreros, Campesinos, Estudiantes del Istmo (COCEI) (Miano, 2002: 216).

5. Xabizende proviene de $x a$ ('lugar') y bizende ('San Vicente'), es decir, 'lugar de San Vicente', el patrón de la ciudad. Para los mexicas, era Iztacxochitlán (iztac: 'blanco', xochilt: 'flor' y tlan: 'abundancia', es decir, 'donde abundan las flores blancas') (Miano, 2002: 37). En 1487, Sahagún recoge un tal Xochitlán (Peterson, 1968). Los zapotecas se dicen a sí mismos binnizá, que significa 'gente de las nubes' (Miano, 2002: 102-103).

6. En la película Muxes, auténticas intrépidas buscadoras de peligro (2005), uno de lo personajes dice que en su familia lo aceptan por ser el hermano mayor, no por su condición de muxe.

7. Marina Meneses, en Ramo de fuego (2000).

8. Ver: McAdams, McCarthy y Zald (1999); Tarrow (1997); Snow, Benford y Hunt (1993), e Ibarra y Tejerina (1998). 
simbólico de Goffman (1974), que lo interpreta como un elemento central en la formación de la identidad y en la definición de los sujetos colectivos. El «enmarque» es el resultado agregado de experiencia personal, memoria colectiva y prácticas objetivadas que habitualmente asociamos al concepto de «cultura». Esta categoría analítica se entiende hoy como un elemento central en la formación de la identidad de los actores sociales y en su «actuación social» (performance). Esta forma de operar tiene como finalidad proyectar una imagen ante los demás que genere ciertas impresiones y formas de acción en la «audiencia».

La argumentación que a continuación se desarrolla intenta describir las dimensiones y las estrategias centrales de «enmarcamiento» en el discurso ideológico en torno al sistema de sexo y género juchiteco, a partir del análisis de los discursos de ciertos actores sociales significativos. Fundamentalmente, se han entrevistado individual y colectivamente a mujeres de clase media vinculadas a los ámbitos político, intelectual y artístico, cuyos discursos se han complementado con otras entrevistas (menor número) a hombres, muxes y ngui'u. La elección preferente de estos grupos sociales de clases medias se debió a que son ellos quienes poseen una situación que les proporciona una perspectiva de conflicto entre tradición y modernidad y una visión crítica hacia todo movimiento de cambio social. Todo ello nos ha permitido conocer los procesos sociales de interpretación de la realidad y asignación de significado dominantes entre la población juchiteca.

\section{Investigaciones previas}

El protagonismo de la mujer juchiteca en la vida económica, social y cultural, la gran autonomía respecto al hombre, la gran autovaloración, el prestigio, junto con la autoridad familiar y social que poseen en esta comunidad, provoca que ellas dominen el sistema de socialización comunitario y el sistema festivo, condición «atípica» frente a otras mujeres indígenas zapotecas ${ }^{9}$. Sin embargo, los diversos estudios que se han realizado con el fin de comprender las causas de esta singular realidad, han discrepado en la manera de caracterizar esta sociedad.

El trabajo de Anya Peterson Roice (1968) dibuja un Juchitán donde, a pesar de la continua interacción histórica de los grupos zapotecas del Istmo, se ha mantenido una "cultura indígena distintiva» (Peterson, 1968: 55), el denominado «estilo zapoteca» (1968: 60), que se concretiza en la vestimenta de las mujeres, el uso del idioma zapoteco, el arte, la producción material artesanal, el calendario de festividades, la gastronomía, las flores emblemáticas, etc., que derivan de formas históricamente sincréticas. Para esta autora, el «estilo zapoteco» fue elaborado a comienzos de la segunda mitad del siglo XIX, alcan-

9. En el estudio que realizó Lynn Stephen (1998) sobre las mujeres zapotecas de Teotitlán del Valle, en la zona central de Oaxaca, se subraya la situación de subordinación, desigualdad y explotación que sufren las mujeres en el hogar y en la comunidad. 
zando la cúspide de desarrollo del porfiriato $(1879-1910)^{10}$. Esta autora afirma que el prestigio y la satisfacción de la población juchiteca frente a su «identidad colectiva» descansa en la buena gestión que han realizado las clases medias y altas del llamado "estilo» o «identidad» zapoteca como estrategia para conservar su poder político y económico (1968: 204).

En los años setenta, Beverly Newbold Chiñas $(1975,1992)$ estudia la comunidad istmeña de San Juan Atempa, y concluye que existe un sistema matrifocal, donde la madre es la figura central de la sociedad, en tanto que el rol que cumple es cultural y afectivamente estructural y central (Miano, 2002: 59).

Más recientemente, durante la década de los noventa, un grupo de investigadoras dirigidas por Verónica Bennholdt-Thomsen aborda el estudio del sistema de género en Juchitán desde el feminismo "de la diferencia» y de la corriente "maternal», pues su trabajo se inspira en la idea de que las mujeres han desarrollado un sistema moral distinto al de los hombres, en base a la responsabilidad, los afectos y la "ética del cuidado» (Chodorow, 1978; Gilligan, 1982; en Beltrán y otros, 2001: 244-246) ${ }^{11}$.

Para estas autoras, en Juchitán existe un matriarcado contemporáneo, en donde toda la sociedad gira en torno a dos elementos principales: la figura de la cultura de la «madre fuerte» y la «economía de la reciprocidad» (BennholdtThomsen, 1997: 1, 127). El primer elemento se basa en la idea de que «[...] las diferencias hombre-mujer son creadas por la desigualdad social y no al revés» (Rosaldo, 1980), por ello, en Juchitán asistimos a una sociedad igualitaria, porque lo que hacen las mujeres es considerado socialmente importante, no «a pesar» de que ellas lo hacen, sino «porque» ellas lo hacen (BennholdtThomsen, 1997: 39). El segundo elemento gira en torno al sistema económico juchiteco de "producción de subsistencia", autoconsumo y sostenibilidad, que se concretan en la satisfacción de las necesidades reproductivas y de seguridad, un sistema de prestigio social no basado en la acumulación, sino en la redistribución de riqueza través del «sistema de fiestas», reguladora y garante de los intercambios redistribuidores (a modo de potlach) (Mauss, 1974), una red de solidaridad basada en los lazos de parentesco, donde los precios se deter-

10. Las fiestas principales del pueblo se llaman «Velas» y se celebran durante todo el año, aunque casi todas se concentran en el mes de mayo, coincidiendo con la siembra y el inicio del ciclo agrícola. Se realizan en honor a un santo, a un producto, a un oficio, a una familia, a un nombre o a un animal. La "Vela» es un gran baile que dura hasta el amanecer, al que acuden las mujeres con su traje típico, y donde se come, se bebe y se baila en abundancia. $\mathrm{Al}$ otro día se celebra una misa en honor al santo con un almuerzo ofrecido por los mayordomos y también se festeja la «lavada de olla». Las Velas titulares mayores de finales de mayo cuentan con la «Regada de frutas» o «Regada de flores», un desfile de carros adornados con flores que transitan por la ciudad, regalando objetos domésticos a la población (anteriormente eran frutas) (Miano, 2002: 131).

11. Numerosos estudios antropológicos han demostrado la diversidad interpretativa frente a la maternidad en diferentes culturas, es como una construcción cultural. La institución de la "cuvada» o la relación entre hombre y fecundidad de los hua de Papua Nueva Guinea o los kurtatchi del Pacífico son ejemplos claros en este sentido (Paige y Paige, 1981; Meigs, 1976; Blackwood, 1934, en Moore, 1991: 43) 
minan en función de la "cuenta de la reciprocidad» y un valor de lo monetario subordinado a las relaciones sociales. Este procedimiento garantiza la igualdad social y la inexistencia de hambre en la comunidad.

El último enfoque teórico que se analiza se refiere a la propuesta de la antropóloga Marinella Miano Borusso (2002). Desde un planteamiento crítico con las contribuciones precedentes, esta autora discrepa de los postulados «matriarcales» y matrifocales». Miano critica el modelo "matrifocal» de Chiñas y «matriarcal» de Bennholdt-Thomsen, porque cree que el poder de la madre se restringe sólo a ciertos espacios (hogar y mercado) y a mujeres que ya han demostrado su abnegación maternal, han cumplido con la "costumbre» y ya no están en periodo fértil (2002: 59). Impugna el concepto de «economía de subsistencia», que reemplaza por el concepto de «economía de prestigio, trueque e intercambio», cuestionando la reciprocidad horizontal (guendalisaa: 'ayuda mutua'; guenda rakanesaa: 'tekio') debido a las excesivas diferencias sociales de las redes de solidaridad e intercambio.

Esta autora considera que, pese a la hegemonía social y económica de las mujeres, éstas también sufren situaciones de subordinación en cinco espacios muy significativos.

El control social de la "sexualidad" de la mujer es mayor que en el hombre $^{12}$, la moral sexual es más permisiva para los hombres y son menos aceptadas las nguiu que los muxe’. En el «hogar», también se desarrollan prácticas que cargan a las mujeres con mayores responsabilidades que a los hombres. También la subordinación se percibe en la diferenciación del proceso de «socialización primaria por género", donde, en la infancia, el niño goza de más libertad y la niña debe ajustarse a ciertas obligaciones y responsabilidades. Los espacios de poder político formal están restringidos para las mujeres, lo que contrasta con la alta participación que ellas han tenido en las movilizaciones sociales y políticas. Por último, en el ámbito de la «alta cultura», se observa la clamorosa ausencia de las mujeres en las artes institucionalizadas, algo que resulta paradójico, pues son ellas (junto con los muxe) las protagonistas de las «artesanías» tradicionales de Juchitán.

Para finalizar, se constata que todas estas autoras coinciden en resaltar la igualdad y el poder social de la mujer juchiteca en las estructuras económicas, sociales y culturales de esta comunidad, frente a lo que ocurre con las mujeres mexicanas y zapotecas, pese a las contradicciones que también se observan en el ámbito cultural, afectivo-sexual y político juchiteco.

12. El casamiento va acompañado del «rito de la desfloración», donde la mujer demuestra su «valor» en base a su virginidad. La mujer «huye» (bixoone cabe) a casa del futuro esposo, y posteriormente informa a la familia de ambos. Entre comida, ruido y música, los parientes esperan a que el hombre, en una habitación de la casa, rompa el himen de la mujer con el dedo. Posteriormente, moja un pañuelo blanco con la sangre vertida y lo exhibe ante ambas familias y delante de los antepasados en el altar familiar. Para Marina Meneses, de esta forma, la mujer se «protege» de las intenciones del varón, al garantizarse el compromiso de éste (Meneses, en Bennholdt-Thomsen, 1997: 113). 


\section{Las ideologías sexuales entre los zapotecas del Istmo}

La originalidad del sistema de sexo y género en Juchitán nos hace reflexionar en torno a las causas que han hecho posible la existencia de un sistema de géneros simétrico e igualitario. Las variables que hemos considerado para responder a ello son principalmente tres: económica, social e ideológico-cultural.

Es indiscutible que la autonomía económica de la mujer teca, su papel en la vida social pública y en las costumbres y las tradiciones son factores fundamentales para entender la equidad de géneros presente en esta sociedad. Sin embargo, se considera que son condiciones necesarias, pero no suficientes para explicar el grado de paridad social. ¿Qué otras condiciones deben producirse para que se haya desarrollado un sistema de sexo y género tan singular? En esta investigación, se ha apostado por considerar como hipótesis la influencia de la ideología de sexo y género propia de la intersubjetividad juchiteca para explicar este hecho social.

Siguiendo planteamientos weberianos, la «ideología cultural de género» es uno de los indicadores fundamentales para saber si una sociedad es más o menos jerárquica respecto a las relaciones sociales basadas en las identidades sexuales (Sacks, 1979; Burton, 1985; en Beltrán y otros, 2001: 49). Por ejemplo, el patriarcado utiliza el desprestigio de todo aquel espacio feminizado para reforzar su hegemonía. En esta investigación, se ha optado por el estudio de la ideología sexual, entendida como un sistema de creencias "naturalizadas" sobre los hombres y las mujeres. A través de este análisis, se pretende deducir si realmente la variable ideológica ha sido determinante para explicar la germinación de un modelo social sexogenérico sin situaciones de subordinación de gran calado.

Las «ideologías sexuales» que se han identificado en los discursos analizados se resumen en cuatro tipos: la complementariedad armónica, el matricentrismo comunitario, el matriarcado y el discurso crítico. A continuación, se desarrolla cada uno de los contenidos de los mismos:

\section{A) Discurso de la complementariedad armónica}

En esta narración, dominante en una gran parte de la población, se considera que existe una complementariedad perfecta y natural entre los tres géneros institucionalizados (mujer, hombre, muxe), los cuales poseen responsabilidades, funciones, obligaciones, derechos y cuotas de poder equivalentes. Como se recoge en esta frase: «[...] el hombre y la mujer tienen el mismo poder, donde manda el hombre no manda la mujer, y donde manda la mujer no manda el hombre».

Esta visión esencialista supone que la mujer, el hombre y el muxé poseen características, roles y atributos inmutables y naturales en los diferentes ámbitos de la vida. En la economía, la mujer «ayuda» al marido a llevar el sustento familiar, siente la necesidad de auxiliar a su pareja para mantener a los hijos: «[... las actividades de la mujer y el hombre se complementan para poder sos- 
tener a la familia», "[la mujer y el hombre poseen] responsabilidades compartidas en la casa, en la estabilidad social y familiar...». En la política, hombres y mujeres son compañeros o "hermanos» que se ayudan a favor de una causa colectiva común. La mujer participa en política junto a los hombres, a los que acompaña para caminar juntos: «[...] el hombre se da su lugar, pero también le da su lugar a la mujer». El varón acaba ocupando los puestos de toma de decisiones específicos del poder político formal, y la mujer realiza un trabajo fundamental, aunque de carácter «auxiliar», el "[...] trabajo de hormiguitas», de «[...] picar piedras», lo que la hace poseedora de «autoridad moral» propia: "[...] somos como una yunta de ganado; el ganado si no jala parejo, no jala».

En el ámbito de la cultura, existe un reparto equilibrado: si el hombre ocupa mayoritariamente las esferas de la cultura institucionalizada y la mujer no, es porque en ella desarrolla su espíritu artístico en la vida cotidiana: «[...] ella misma es un arte» que desarrolla a través de su indumentaria.

En el ámbito de la sexualidad, existe una heteronormatividad y homonormatividad diferente para hombres y mujeres, con el único objetivo de que la familia y la comunidad se reproduzcan y funcione. Así, la mujer se vale de estrategias como el "rito del desfloramiento» para asegurar la seriedad y la pervivencia en el tiempo de la relación matrimonial. Si el muxe’ no es estigmatizado o discriminado, es porque cumple con el «rol tradicional» de sustento económico familiar y cuidador de los miembros dependientes de la familia: «[...] él es el que te va a ver [en la vejez]».

\section{B) Discurso del matricentrismo comunitario}

Cercana a la anterior perspectiva de la «complementariedad armónica» entre hombres, mujeres y muxes, emerge otro discurso que enfatiza los aspectos biosociales de cada sexo y género y, fundamentalmente, la capacidad biológica de la mujer y su condición de «madre», que es sacralizada, puesto que opera como fundamento esencial de la organización social juchiteca: «[...] es matriarcado porque manda la mama» ${ }^{13}$. Ellas son principalmente las «reproductoras» de la tradición. Desde esta perspectiva, la mujer se ocupa de los hijos y de la familia por cuestiones biológicas (embarazo y amamantamiento), es el «[...] primer amante» de su hijo: "[...] el niño le tiene un cariño natural a la mama y el padre se lo tiene que ganar». También se considera que la mujer madura antes que el hombre desde el momento en que se queda embarazada, aunque sea una adolescente, lo cual confiere un tratamiento reverencial y sagrado a la «maternidad»: «[...] la mujer es madre de un millón y el hombre es padre de nadie». Y es estimada porque «[...] tiene más valor que el hombre, porque prefiere al hijo antes que una relación; el hombre no, prefiere una relación a comprometerse tanto [sacar adelante a un hijo]». La madre está presente en la vida de todas las personas entrevistadas de forma preeminente, la mama «sacrifica-

13. Declaraciones en la película Ramo de fuego (2000). 
da» que trabaja duro para sacar adelante a los hijos: «[...] no sé de dónde sacaba para darnos de comer», que funciona como el principal apoyo emocional y referente del buen comportamiento social; en muchos casos, «[...] es mi bandera [...] por ahí quiero caminar, por ese camino que ella ha hecho» ${ }^{14}$. Este «punto de vista maternal» también es empleado en el ámbito económico, donde la mujer se ve "[...] obligada a buscarle por todos los lados» para sacar adelante a la familia.

Si la mujer funciona y participa en el ámbito público (social y político) extendiendo su "rol de cuidadora», tratando a la comunidad como si fuera la "[...] madre de muchos hijos», con el fin de servir al pueblo (como si fueran sus retoños), más que por intentar desarrollar un proyecto personal. Por ello, los vínculos familiares y emocionales suelen determinar la participación y las fidelidades políticas de las mujeres.

El sistema de los sexos también se trata de forma sociobiologizante, así se acude a causas sobrenaturales o biológicas para explicar la "proliferación de géneros» en Juchitán: «[...] Dios nos lo mandó así», «lo que eres no lo puedes dejar de ser», o "[ser muxe'] viene de raza, hay muchos en una familia, aunque se hayan casado" y la relación con los otros sexos se entiende por parte de las mujeres como complementos, no conflictos: «[...] el muxe' no es competencia para la mujer, porque el hombre no lo toma en cuenta, sólo se va con él por el dinero [...] [si se va con un muxé] ¡Qué bueno! Así somos comadres».

\section{C) Discurso del matriarcado}

La estructura cognitiva de este discurso, minoritario entre la población juchiteca, se centra en la afirmación de la existencia de un matriarcado en Juchitán, «[...] negarlo sería como querer tapar el sol con un dedo».

Esta percepción está muy vinculada a la exaltación de la figura de la mujer juchiteca, como «icono» social, elemento común en todos los discursos analizados, pero que en este caso resulta más amplificado: la mujer es una heroína fuerte, valiente, orgullosa y socialmente muy valorada. Es ella quien asume la responsabilidad de todo, ella toma sus "propias decisiones» (no espera a conocer la opinión del hombre), es la «[...] que se enfrenta a todo [...] le busca por todos lados», "no vamos a esperar a que el hombre nos dé, nosotras vamos a buscarlo» y muchas veces son ellas las únicas proveedoras del hogar. Al hombre se lo considera más irresponsable que a la mujer, pues parte de su responsabilidad la delega en ella: "[...] la mujer puede sacar adelante sola a sus hijos, a veces mejor que con una pareja, porque es fuerte, trabajadora, luchadora, inteligente, no se deja vencer y es muy sacrificada [hasta sacrifica su propio cuerpo]». Desde esta perspectiva, se considera que si existen relativamente pocos casos de violencia intrafamiliar en Juchitán es porque la mujer «no se

14. Es común que, cuando se casan dos jóvenes estudiantes y van a tener un hijo, ella deja los estudios y se dedica a buscar trabajo y él sigue estudiando, con el apoyo de suegros y padres. 
deja», si el hombre le pega, "es borracho» o es un insensato, está legitimado socialmente que ella lo «corra» de la casa.

Esta ideología matriarcal estima que este modelo social es una herencia prehispánica de los «antepasados», quienes vivían en una sociedad donde las mujeres gozaban de los mismos derechos que el hombre y la diversidad sexual era aceptada «[...] no como en la edad media europea, donde los homosexuales era reprimidos y las mujeres no tenían derechos» y se explica esta pervivencia debido a que "[...] el patriarcado históricamente no avanzó y se mantuvieron estructuras matriarcales, donde las mujeres tienen peso en la orientación de la vida [...], tienen fuerza, tienen la posibilidad de ser valoradas y se valora y apoyan cuando tienen hijos» ${ }^{15}$.

Estos planteamientos realzan las peculiaridades de la identidad étnica zapoteca, a modo de "comunidad idealizada» o «arcadia primitiva» (Smith, 2000) que deriva en la reivindicación de una autonomía política para esta región del Istmo ${ }^{16}$.

\section{D) Discurso crítico}

Desde esta óptica crítica, muy minoritaria y propia de grupos más occidentalizados, se cuestiona la existencia de un matriarcado en Juchitán y de una armonía complementaria entre los géneros. Se denuncia la masculinización de los ámbitos de poder político y cultural y las excesivas limitaciones que sufre la mujer en el ámbito afectivo y sexual. Además, delega sus "proyectos personales» en aras del beneficio a la comunidad, la familia o los hijos, y les resulta difícil conciliar la casa, los hijos, el trabajo, la vida social, política, etc. En el ámbito económico, la aportación de la mujer le permite no estar tan sometida como en el resto del país, pero finalmente no disfruta de un poder real de decisión: «[...] la mujer juchiteca posee autonomía personal pero no está empoderada». Trabaja dos o tres veces más que el hombre y si algo no funciona «ella tiene la culpa», pese a que "[...] la mujer es independiente económicamente, no lo es emocionalmente de los hombres y depende de sus decisiones». Este discurso destaca que la problemática de violencia intrafamiliar se aborda como un mal menor donde no se defiende a la víctima mujer: «[...] la mama de la esposa es quien lo defiende a él», "[...] las abuelas convencen a las mujeres para que aguanten, que esa situación es normal, lo importante es que [tu esposo)] te dé dinero" o es resuelta tradicionalmente a través de procesos de conciliación y negociación, $\mathrm{y}$ «[...] unir a la familia a toda costa, pese a dañar a los individuos».

En el ámbito político, perciben la existencia de un "complot masculino» para que las mujeres no destaquen. La mujer es fuerte y valiente, pero no

15. Declaraciones de Maria Meneses, socióloga juchiteca en la película Ramo de fuego.

16. Este planteamiento político se ha desarrollado en la revista Istmo Autónomo, de carácter cultural y editada por el Comité Pro Independencia del Istmo Che Glorio Melendre de forma bimestral. 
manda, porque no posee el poder político formal. En la COCEI, «[...] los líderes dividían a las mujeres», lo cual provocaba cierta misoginia entre ellas mismas: "[...] porque no nos apoyamos, hay rivalidad entre mujeres, cada facción tiene a sus mujeres», lo que hace que prevalezcan las fidelidades a los lazos familiares y emocionales, más que al ideario político.

En el ámbito de la sexualidad, es ilustrativo que el famoso «rito del desfloramiento» sea entendido desde el posicionamiento crítico como un "[...] acto de humillación [hacia la mujer]» y que es el que da "[...] arranque al matrimonio». Ella no sabe negociar una sexualidad segura porque el hombre considera que eso denota la infidelidad de su pareja: «[...] la pareja hombre pretende controlar tu vida [...] y quien controla tu cuerpo, controla tu tiempo y controla tu vida», "[...] el machismo es muy arraigado». La mujer que reniega de la tradición, no es valorada ni posee autoridad, ni es respetada socialmente: «no vale, es rechazada».

Esta ideología afirma que hay rasgos de dominación patriarcal en ciertos aspectos de la sociedad juchiteca, pese a que la mujer es considerada un ser con cualidades superiores a los hombres: «[...] las mujeres hacen las cosas diferentes a los hombres, su práctica política no se dirige al corporativismo y a la manipulación». Ante esta realidad desquilibrada e injusta, sólo se puede optar por una salida, que es: «[...] que la mujer despierte y vea el camino que quiere caminar». Este planteamiento parte de un cierto desprecio e infravaloración del hombre como un ser flojo e irresponsable que no debe ser digno de confianza: «[...] Aunque les hagas creer a los hombres que ellos lo están haciendo, que ellos deciden [somos nosotras], les vendemos esa idea», o bien "[...] cuando los hombres tienen dinero, lo malgastan», idea que incluso es compartida por los propios hombres sobre sí mismos: «[...] los sueldos se los damos a la mujer, para que fructifiquen», autopercepción que los confina a una especie de «infantilización» o «adolescencia permanente», llegando incluso a responder a la pregunta sobre cuál es la problemática más generalizada entre los hombres con esta respuesta: «[...] ¿los problemas de los hombres? [Pues que] el hombre no acepta que él es el problema».

En estas cuatro tipologías discursivas encontramos una percepción compartida en torno al imaginario sobre el género. Al contrario que en la ideología patriarcal, que infravalora lo femenino y los «espacios feminizados», en Juchitán se valora y se aprecia a la mujer y su mundo, pues se la considera fuerte, trabajadora, luchadora, amante de la familia, rebelde, cariñosa, maternal, fiestera, orgullosa, hermosa, elegante, alegre y valiente. Todo ello muestra el panorama de la praxis real en torno a los imaginarios femeninos en esta sociedad.

\section{A modo de conclusión}

El estudio de la «otredad» ha sido un espacio enriquecedor y clarificador en el desarrollo de la ciencia occidental. El debate sobre la validez de ciertas categorías y postulados teóricos que se han considerado universales, se ha enri- 
quecido a través del análisis de realidades contemporáneas ajenas a la sociedad europea occidental moderna.

Esta investigación ha pretendido ampliar el panorama en torno al «estado de la cuestión» de la literatura científica que ha reflexionado sobre el sistema de sexo y género en la comunidad zapoteca de Juchitán. La realidad juchiteca presenta una serie de atractivos y retos para las ciencias sociales debido a la singularidad de su sistema de género, su modelo económico no totalmente capitalista y la integración de la diversidad sexual en su seno, entre otros aspectos.

En esta investigación, se ha constatado que en ninguno de los cuatro discursos dominantes estudiados, se justifica la «superioridad» masculina y heterosexual, frente a la «inferioridad» femenina y homoerótica. Esta realidad ideológica ha favorecido que se construya una sociedad no patriarcal ni heteronormativa. La mayor igualdad en las relaciones entre las diversas identidades sexuales se deriva, además, de la preeminencia y autonomía del papel y de las responsabilidades de las mujeres en los ámbitos económicos y socioculturales, y de la existencia de una fuerte cohesión comunitaria que prima las lógicas reproductivas y colectivas frente a las lógicas particularistas.

Considerando que, en el futuro, el interés debe dirigirse al análisis de la controvertida paradoja entre la singularidad de este modelo ginecocrático y los espacios encrucijada de conflicto y subordinación femenina, lo que se propone es seguir profundizando en las características de la identidad, las atribuciones, la ideología, los símbolos, las normas y las instituciones sociales del sistema de género dominante en Juchitán (Scott, 1990).

Sólo a través de la eliminación de los sistemas ideológicos que legitiman las jerarquías de poder en base a criterios de género, económicos, étnicos, de opción sexual, etc. y sólo mediante un nuevo modelo económico sostenible, recíproco y redistributivo, se podrá iniciar un cambio social viable, históricamente marcado en el horizonte «utópico» de la humanidad.

\section{Bibliografía}

Beltrán, E.; Maquieira, V. (eds.); Alvarés, S.; Sánchez, C. (2001). Feminismos: debates teóricos contemporáneos. Madrid: Alianza Editorial.

Bennholdt-Thomsen, V. (1994). Juchitán, la ciudad de las mujeres. México: Instituto Oaxaqueño de las Culturas. Fondo Estatal para la Cultura y las Artes.

Boserup, E. (1970). Women's Role in economic development. Londres: Allen and Unwim.

CAMPBell, H.; GreEN, S. (1999). «Historia de las representaciones de la mujer zapoteca del Istmo de Tehuantepec». En: Estudios sobre las culturas contemporáneas, época IIV, no 9, Colima, junio, p. 89-112.

CampBell, H.; Binford, L.; BARTOlOMÉ, M.; BARABás, A. (ed.) (1993). Zapotec struggles: histories, politics and representation from Juchitán (Oaxaca). Washington y Londres: Smithsonian Institution Press.

Covarrubias, M. (1946). El sur de México. México: INI.

GERHARDS, J. (1995). Framing dimensions and framing strategies: contrasting ideal-and real-type frames. Londres: Social Science Information.

Goffman, E. (1974). Frame analysis. Cambrigde: Harvard University Press. 
Harris, O.; Young, K. (comps.). Antropología y feminismo. Madrid: Anagrama.

Heritier, F. (2002). Masculinolfemenino: El pensamiento de la diferencia. Barcelona: Ariel Antropología.

IBARRA, P.; TeJerina, B. (comp.) (1998). Los movimientos sociales. Madrid: Trotta.

INEGI (1990). Región Istmo, Oaxaca. Perfil sociodemográfico. XI censo general de población y vivienda. México DF: INEGI.

Matus, M. (1978). «Conceptos sexuales entre los zapotecas de hoy». En: La cultura en México, suplemento de Siempre, no 859, agosto.

MAuss, M. (1971). «Ensayo sobre el Don: Forma y razón del intercambio en las sociedades arcaicas». Sociología y Antropología. Madrid: Tecnos.

MCADAMS, D.; MCCARTHY, J.; ZALD, M. (comp.) (1999). Movimientos sociales: perspectiva comparada. Madrid: Itsmo.

Miano, M. (2002). Hombre, mujer y muxé en el Istmo de Tehuantepec. México: Plaza y Valdés. CONACULTA-INAH.

Miano, M. (1993). Viaje a través de la identidad de los zapotecos del Istmo de Tehuantepec. Tesis de Maestría en Antropología Social. México: ENAH.

Moore, H. L. (1991). Antropología y feminismo. Valencia: Ediciones Cátedra. Universidad de Valencia. Instituto de la Mujer.

NeWBOLD ChIÑA, B. (1975). Mujeres de San Juan. La mujer zapoteca del Istmo en la economía. México: SEP.

Newbold Chiña, B. (1992). The Isthmus Zapotecs. A matrifocal Cultural of México. Chico: California State University.

ReINA, L. (1997). «Etnicidad y género entre los zapotecas del Istmo de Tehuantepec, México, 1840-1890». En: ReINA, L. (coord.). La reindianización de América, siglo XIX. México DF: Siglo XXI.

SNOW; HUNT; BENFORD (1993). Framing process and identity construction in collective action. Chicago: Presented at the Annual Meetings of the Midwest Sociological Society.

STEPHEN, L. (1991). Mujeres zapotecas. Oaxaca: Instituto Oaxaqueño de las culturas. Fondo Estatal para la Cultura y las Artes.

TARROW, S. (1997). El poder del movimiento: Los movimientos sociales, la acción colectiva y la política. México DF: Alianza Editorial.

VEGA, E. de la (2005). «Juchitán y las muxes: la bendición de ser gay». Revista Zero, no 72. Madrid.

Películas:

Covarrubias, M. (1940/1998). El sur de México.

GosLing, M. (2000). Ramo de fuego.

IsLAS, A. (2005). Muxes: auténticas intrépidas buscadoras de peligro. 